\title{
Caveolin-1 Deficiency Dampens Toll-Like Receptor 4 Signaling through eNOS Activation
}

\author{
Muhammad K. Mirza, ${ }^{\star \dagger}$ Jun Yuan, ${ }^{\star \dagger}$ \\ Xiao-Pei Gao, ${ }^{* \dagger}$ Sean Garrean, ${ }^{* \dagger}$ \\ Viktor Brovkovych, ${ }^{* \dagger}$ Asrar B. Malik, ${ }^{* \dagger}$ \\ Chinnaswamy Tiruppathi, ${ }^{* \dagger}$ and You-Yang Zhao* \\ From the Department of Pharmacology, ${ }^{*}$ and Center for Lung \\ and Vascular Biology, University of Illinois College of Medicine, \\ Chicago, Illinois
}

Caveolin-1 (Cav1), the scaffolding protein of caveolae, has been shown to play an important role in host defense and inflammation. However, the underlying molecular basis for these actions remains elusive. Here, using double mutant mice with genetic deletions of Cav1 and NOS3, we show that chronic endothelial nitric oxide synthase (eNOS) activation secondary to loss of Cav1 serves a crucial immunomodulatory function through tyrosine nitration-mediated impairment of interleukin-1 receptor associated kinase (IRAK)4, a signaling component required for nuclear factor- $\kappa B$ activation and innate immunity. We observed an eNOS-dependent decrease in the plasma concentration of pro-inflammatory cytokines and marked improvement of survival in Cav1 ${ }^{-/-}$mice following lipopolysaccharide challenge. Activation of eNOS secondary to loss of Cav1 resulted in decreased activation of nuclear factor- $\kappa B$ in response to lipopolysaccharide challenge, and thereby protected the animals from lipopolysaccharide-induced lung injury. IRAK4 was prominently nitrated in Cav1-deficient endothelial cells, whereas eNOS deletion in Cav1-deficient endothelial cells resulted in marked decrease of IRAK4 nitration and restored the inflammatory response after lipopolysaccharide challenge. Furthermore, in vitro nitration of IRAK4 resulted in impairment of the kinase activity. Thus, eNOS activation secondary to loss of Cav1 signals dampening of the innate immune response to lipopolysaccharide through IRAK4 nitration and the resultant impairment of kinase activity, and consequently mitigates inflammatory lung injury. (AmJ Pathol 2010, 176:2344-2351; DOI: 10.2353/ajpath.2010.091088)
Regulation of innate immunity, the primary line of defense against non-self, plays a key role in limiting disease. ${ }^{1,2}$ The well-being of higher eukaryotes depends on the appropriate initiation and termination of the immune response. ${ }^{2}$ Innate immune responses are comprised of phagocytosis of bacteria by macrophages and neutrophils, release of antimicrobial peptides, hydrolytic enzymes, and reactive oxygen intermediates by phagocytes, activation of complement system, and cytotoxic activity of natural killer cells against infected target cells. ${ }^{3}$ These rapid and nonspecific responses are elicited by surveillance of Gram-negative bacterial lipopolysaccharide (LPS), Gram-positive bacterial peptidoglycans and lipoteichoic acid-associated molecules, mycobacterial muramyl dipeptides, fungal glucans, and bacterial CpGrich nucleotides. ${ }^{4}$ Interactions between pathogens and their hosts are initiated by the activation of pathogen recognition receptors, the toll-like receptors (TLR). As a potent activator of innate immunity, LPS activates TLR4 signaling, a critical event in the immune response to Gram-negative bacteria and in the etiology of endotoxic shock and acute lung injury. 5,6

TLR4 binding by LPS recruits the adaptor molecule MyD88 through the TIR domain of TLR4 to initiate either MyD88-dependent or MyD88-independent pathways. ${ }^{6,7}$ MyD88 recruits serine-threonine kinases interleukin(IL)-1R-associated kinase (IRAK) 4 and IRAK1.,89 IRAK4 then phosphorylates IRAK1 resulting in recruitment of TRAF6 to the receptor complex ${ }^{10}$ and activation of transforming growth factor- $\beta$-activated kinase (TAK1), a member of the mitogen-activated protein kinase kinase family. ${ }^{11}$ The activation of TAK 1 leads to the activation of nuclear factor (NF)- $\kappa \mathrm{B}$, a regulator of immunity and inflammation, ${ }^{12,13}$ which in return results in production of an array of pro-inflammatory cytokines, chemokines, and adhesive molecules, such as tumor necrosis factor (TNF)- $\alpha$, macrophage inflammatory protein $1 \alpha(\mathrm{MIP}-1 \alpha)$, and intercellular adhesion molecule (ICAM)-1.2,14,15 The

\footnotetext{
Supported by NIH grant R01HL085462 to Y.-Y.Z.

Accepted for publication December 29, 2009.

Address reprint requests to You-Yang Zhao, Ph.D., Department of Pharmacology, University of Illinois College of Medicine, 835 South Wolcott Avenue, E403-MSB, M/C 868. Chicago, IL 60612. E-mail: yyzhao@uic.edu.
} 
critical role of IRAK4 in TLR-mediated pathways was demonstrated in IRAK4 null mice and in humans with IRAK4 deficiency. 8,16,17 IRAK4 deficiency resulted in a severe impairment of TLR signaling.

Nitric oxide (NO) plays an important role in host-defense and inflammation. ${ }^{18-20} \mathrm{NO}$ exerts its effect on innate immunity by direct antimicrobial activity and indirectly through reaction with reactive oxygen species and formation of antimicrobial metabolites such as peroxynitrite and nitrogen dioxide. ${ }^{18}$ The antimicrobial activity is mainly mediated by inducible NO synthase (iNOS)-derived NO. Endothelial NOS (eNOS)-derived NO blocks platelet and neutrophil activation, serves as a regulator of leukocyte recruitment, inhibits several features of mast cell-induced inflammation. ${ }^{21,22}$ eNOS activity and NO release is mainly regulated by post-translational modifications by fatty acid and phosphorylation as well as protein-protein interaction with other effector molecules including heat shock protein 90 and caveolin-1. ${ }^{23}$ Caveolin-1 (Cav1) is the scaffolding protein of caveolae in many non-muscle cell types including endothelial cells. ${ }^{24}$ Cav1 binding to eNOS in the basal state suppresses eNOS activity, whereas on agonist activation, eNOS dissociates from Cav1 and synthesizes NO. ${ }^{25}$ Plasma NO levels were markedly increased in Cav1 ${ }^{-1-}$ mice. ${ }^{26}$ Cav1-deficient mice exhibited multiple phenotypes: pulmonary hypertension, cardiomyopathy, pulmonary hypercellularity, and resistance to LPS-induced acute lung injury. ${ }^{26-29}$ The pathology may be ascribed to the interaction of Cav1 with signaling molecules such as receptor and non-receptor tyrosine kinase receptors, G protein-coupled receptors, GTPases, and components of the mitogen-activated protein kinase, and eNOS. ${ }^{30}$ Our recent study has shown that persistent eNOS activation secondary to Cav1 deficiency induces pulmonary hypertension through protein kinase $\mathrm{G}$ nitration and resultant impairment of its kinase activity. ${ }^{31}$ However, the precise pathophysiological role of Cav1eNOS interaction in modulating innate immunity and LPSinduced inflammatory lung injury remains unclear because the approaches taken have used nonselective inhibitors. Here, using mice with genetic deletions of both Cav1 and NOS3 (DKO), we demonstrate the critical in vivo role of Cav1 in regulating the lung's innate immune response to LPS by its ability to modulate the production of eNOS-derived NO. To our knowledge, we provide the first evidence that IRAK4 kinase activity is negatively regulated by tyrosine nitration. We showed that the decreased NF- $\kappa \mathrm{B}$ activation and inflammatory lung injury seen in Cav $1^{-1-}$ mice in response to LPS challenge was mediated by eNOS activation-dependent IRAK4 nitration.

\section{Materials and Methods}

\section{Mice}

Mice deficient in either Cav1 or NOS3 were purchased from the Jackson Laboratory (Maine) and bred together to produce the DKO mice. To eliminate any background effects from either $\mathrm{NOS}^{-/-}$or Cav1 ${ }^{-/-}$line on the observed phenotype of DKO mice, F4 or higher generations were used for these studies. Wild-type, Cav1 $1^{-1-}$, DKO, and $\mathrm{NOS}^{-1-}$ mice with matched genetic background were used for all studies. All animals were housed in accordance with guidelines from the American Association for Laboratory Animal Care. Approval for animal care and use in these experiments was granted by the Animal Care and Use Committees of the University of Illinois at Chicago.

\section{Molecular Analysis}

Western blot analyses were performed using antibodies against ICAM-1 (1:1000, Santa Cruz, California), IRAK4 (1:500, Imgenex, California), and nitrated tyrosine (1:200, Cayman Chemical, Michigan), respectively. The same blots were reprobed with antibody against glyceraldehyde phosphate dehydrogenase (1:1000, Santa Cruz) as loading control.

\section{Mouse Lung Endothelial Cells}

Primary cultures of mouse lung endothelial cells were established using cells immunoselected from mouse lungs as previously described. ${ }^{32}$ Briefly, a cell suspension was prepared from lungs by digestion with collagenase $(1 \mathrm{mg} / \mathrm{ml})$ and dispase $(0.5 \mathrm{mg} / \mathrm{ml})$ for 30 minutes twice, followed by filtration using $70 \mu \mathrm{m}$ and $40 \mu \mathrm{m}$ nylon filters. Endothelial cells were then selected using a rat antibody to mouse CD-31 (Millipore, Massachusetts) and a secondary antibody coupled to magnetic beads (Miltenyi Biotec, Bergish Gladbach, Germany). Purified endothelial cells were plated on matrigel-coated 6-well plate and expanded in $0.2 \%$ gelatin-coated 6-well plate in EBM2 complete growth medium (Lonza, Basel, Switzerland).

\section{Cytokine and Chemokine Expression Profile}

Fifty microliters of plasma or protein lysates (100 to 150 $\mu \mathrm{g}$ ) extracted from mouse lungs using radioimmunoprecipitation assay buffer (RIPA) were used for expression profiling of TNF- $\alpha$, MIP- $1 \alpha$, and IL-10 using the customer selected mouse Bio-Plex Cytokine Assay (Bio-Rad Labs, California). The assay was performed using the Bio-Plex System (Bio-Rad Labs) following the manufacturer's instructions.

\section{Electrophoretic Mobility Shift Assay}

$\mathrm{NF}-\kappa \mathrm{B}$ activation was determined as previously described. ${ }^{29}$ Briefly, nuclear extracts $(10 \mu \mathrm{g})$ were incubated with $1 \mu \mathrm{g}$ of poly (deoxyinosinic-deoxycytidylic acid) in a binding buffer [10 mmol/L Tris- $\mathrm{HCl}(\mathrm{pH} 7.5), 50$ $\mathrm{mmol} / \mathrm{L} \mathrm{NaCl}, 0.5 \mathrm{mmol} / \mathrm{L}$ dithiothreitol, and $10 \%$ glycerol] at room temperature for 15 minutes. End-labeled doublestranded oligonucleotides containing the NF- $\kappa \mathrm{B}$ site (15,000 cpm each) were then added to the mixture and incubated at room temperature for 15 minutes. The sequence of the oligonucleotide was 5'-AGTTGAGGG- 
GACTTTCCCAGGC-3'. It contained the consensus $\mathrm{NF}-\kappa \mathrm{B}$ binding site in the $\lg \kappa \mathrm{L}$ chain enhancer. The labeled nuclear proteins were resolved by polyacrylamide gel electrophoresis using $0.25 \times$ TBE buffer (22 $\mathrm{mmol} / \mathrm{L}$ Tris, $22 \mathrm{mmol} / \mathrm{L}$ boric acid, $0.5 \mathrm{mmol} / \mathrm{L}$ EDTA; $\mathrm{pH}$ 8.4). The gel was then transferred to blotting paper and exposed to film at $-80^{\circ} \mathrm{C}$.

\section{Pulmonary Microvascular Permeability}

Pulmonary microvascular permeability to liquid were quantified by measuring capillary filtration coefficient $\left(\mathrm{K}_{f, C}\right)$ as previously described. ${ }^{32,33}$ Briefly, after the standard 30-minute equilibration perfusion, the outflow pressure was rapidly elevated by $130 \mathrm{~mm} \mathrm{H}_{2} \mathrm{O}$ for 3.5 minutes and was then returned to normal. The lung wet weight changed in a ramp-like fashion, reflecting net fluid extravasation. At the end of each experiment, lungs were dissected free of nonpulmonary tissue, and dry weight was determined. $K_{\mathrm{f}, \mathrm{C}}\left(\mathrm{ml} / \mathrm{min} / \mathrm{cmH}_{2} \mathrm{O} / \mathrm{dry} \mathrm{g}\right)$ was calculated from the slope of the recorded weight change normalized to the pressure change and to lung dry weight.

\section{Histological Analysis}

Following PBS perfusion, the lung tissues were fixed for 5 minutes by instillation of 10\% PBS-buffered formalin through tracheal catheterization at a transpulmonary pressure of $150 \mathrm{~mm} \mathrm{H}_{2} \mathrm{O}$. After tracheal ligation, harvested lungs were fixed with $10 \%$ buffered formalin overnight at $4^{\circ} \mathrm{C}$ with agitation. After paraffin processing, the tissues were sectioned at 4 to $5 \mu \mathrm{m}$ thick, and stained with H\&E. A computer-based stereological method was used to quantify the number of leukocytes in lung interstitial tissue. The system consisted of a microscope, a computer-controlled $x-y-z$ motorized stage, a high sensitivity video camera, a computer-assisted image capture, and a stereological software program (stereo investigator) from MicroBrightField (Vermont). Scores were assessed as previously described. ${ }^{32,34}$

\section{In Vitro Nitration and Kinase Assay}

Purified recombinant human IRAK4 (Millipore, Massachusetts) was incubated with peroxynitrite (Calbiochem, California) at various concentrations to induce tyrosine nitration. Briefly, peroxynitrite was diluted into $0.1 \mathrm{~N} \mathrm{NaOH}$, and then added into the solution containing $50 \mathrm{mmol} / \mathrm{L}$ $\mathrm{KH}_{2} \mathrm{PO}_{4}(\mathrm{pH} 7.4)$ and $0.05 \mu \mathrm{g}$ of IRAK4. Equal amount of $0.1 \mathrm{~N} \mathrm{NaOH}$ (less than $2 \%$ of total volume) without peroxynitrite was added into control reactions. The reactions were maintained at room temperature for 15 minutes. And then an aliquot $(20 \mu \mathrm{l})$ of the reaction product was added into $30 \mu \mathrm{l}$ kinase buffer (20 mmol/L HEPES, pH 7.6, 20 $\mathrm{mmol} / \mathrm{L} \mathrm{MgCl}, 20 \mathrm{mmol} / \mathrm{L} \beta$-glycerophosphate, $20 \mathrm{mmol} / \mathrm{L}$ paranitrophenylphosphate, $1 \mathrm{mmol} / \mathrm{L}$ EDTA, $1 \mathrm{mmol} / \mathrm{L}$ sodium orthovanadate, and $1 \mathrm{mmol} / \mathrm{L}$ benzamidine) for kinase activity assay and another aliquot was used for Western blotting to detect tyrosine nitration with antinitrotyrosine antibody.
In vitro activity of IRAK4 kinase was determined by measuring the transfer of the $\left(\gamma^{-{ }^{3}} \mathrm{P}\right)$ phosphate group of ATP to the specific IRAK4 substrate, myelin basic protein (Sigma-Aldrich, Missouri). The assay was performed in a total volume of $50 \mu \mathrm{l}$ containing $5 \mu \mathrm{mol} / \mathrm{L}$ ATP, $1 \mu \mathrm{g}$ of myelin basic protein, $1 \mu$ of $\left(\gamma_{-}^{32}\right.$ P)ATP, and incubated at $37^{\circ} \mathrm{C}$ for 20 minutes. The reaction was terminated by spotting $40 \mu \mathrm{l}$ aliquots of mixture on phosphocellulose paper (P81, Whatman, New Jersey). Following four washing with $75 \mathrm{mmol} / \mathrm{L}$ of ice-cold phosphoric acid solution, the papers were then dried and counted in a liquid scintillation counter. Five microliters of the reaction mixture was directly spotted on the phosphocellulose paper without washing for determination of the $\gamma$-32P-ATP specific activity. IRAK4 activity is expressed as picomoles of ${ }^{32} \mathrm{P}$ incorporated into IRAK4 substrate per min per microgram protein and normalized to control.

\section{Statistics}

Differences between groups were examined for statistical significance using Student's t-test, except for statistical analysis in the mortality study following LPS challenge, which was performed with the Peto-Peto-Wilcoxon test. $P<0.05$ denoted the presence of a statistically significant difference.

\section{Results}

\section{Genetic Deletion of NOS3 in Cav1 $1^{-/-}$Mice Restores Production of Pro-Inflammatory Cytokines following LPS Challenge}

$\mathrm{NOS3}^{-1-}$ mice ${ }^{35}$ were mated into the background of $\mathrm{Cav1}^{-/-}$mice ${ }^{28}$ to produce a mouse model with genetic deletions of both Cav1 and NOS3. As shown in Figure 1A, there was twofold increase in plasma NO concentration in Cav1 ${ }^{-1-}$ mice, as compared with wild-type mice, whereas plasma NO concentration in DKO mice were significantly decreased and similar to those in $\mathrm{NOS3}^{-/-}$ mice. To investigate the role of Cav-1-regulated eNOS activity in TLR4 signaling, we first examined the production of TNF $\alpha$, cytokine involved in innate immunity, ${ }^{15}$ in mice challenged with LPS at a dosage of $7.5 \mathrm{mg} / \mathrm{kg}$ body weight (BW) by i.p. injection for 2 hours. Cav1 ${ }^{-1-}$ mice produced significantly less TNF $\alpha$ in response to LPS compared with wild-type mice (Figure 1B). However, the reduction in TNF $\alpha$ production was restored in DKO mice in response to LPS challenge (Figure 1B). We observed a similar pattern in the plasma concentration of MIP- $1 \alpha$ in response to LPS challenge. The reduced production of MIP-1 $\alpha$ in $\mathrm{Cav}^{-1-}$ mice was fully restored in DKO mice following LPS challenge (Figure 1C). In contrast, the plasma concentration of non-inflammatory cytokine IL-10 were similar among wild-type, Cav1 ${ }^{-/-}$and DKO mice in response to LPS challenge (Figure 1D). 


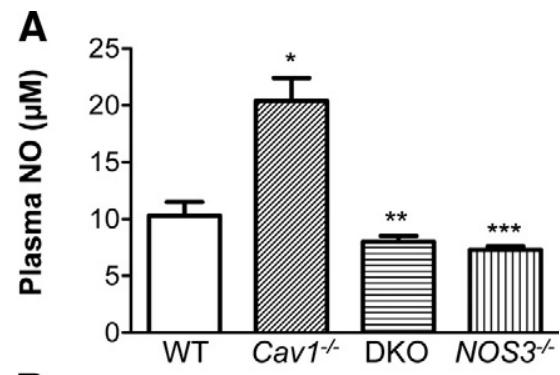

B

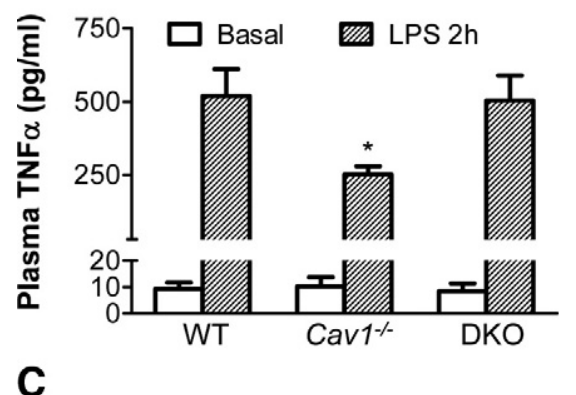

C
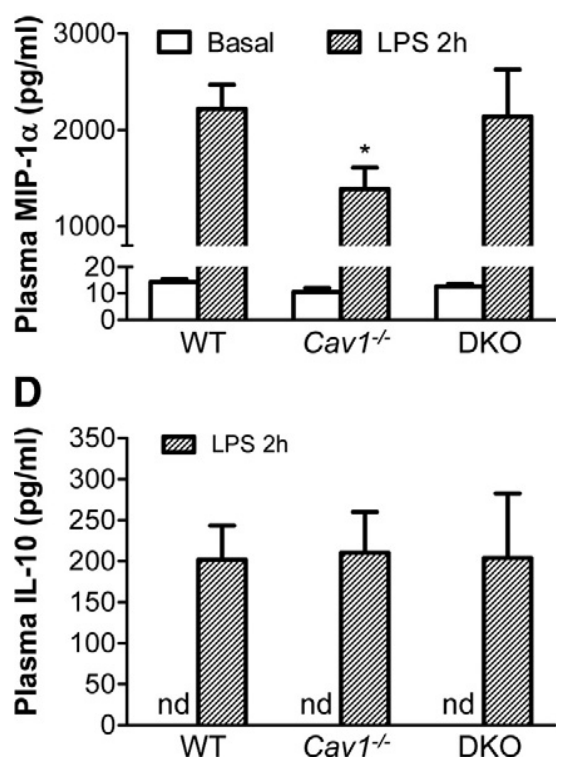

Figure 1. Restoration of plasma levels of pro-inflammatory cytokines in DKO mice following LPS challenge. A: Plasma NO levels. Plasma was collected from 3-month-old mice and NO was determined with Griess reagent. Data are expressed as mean $\pm \mathrm{SD}(n=3$ to 5$) .{ }^{*} P<0.001$ Cav $1^{-/-}$versus wild-type (WT); ${ }^{* *} P<0.05$, DKO versus wild-type; ${ }^{* * *} P<0.01 \mathrm{NOS} 3^{-1-}$ versus wild-type. B: Plasma levels of TNF $\alpha$. Blood were collected from mice at either basal or 2 hours post-LPS challenge $(7.5 \mathrm{mg} / \mathrm{kg} \mathrm{BW})$ through right ventricle puncture. Plasma $(50 \mu \mathrm{l})$ was used for the mouse Bio-Plex cytokine assay. Data are expressed as mean $\pm \mathrm{SD}(n=3$ to 5$)$. ${ }^{*} P<0.05$ Cav $1^{-1}$ versus DKO or wild-type. Two hours post-LPS challenge, plasma levels of TNF $\alpha$ were significantly lower in $C a v 1^{-/-}$mice, compared with wild-type mice whereas restored in DKO mice. C: Plasma levels of MIP-1 $\alpha$. Data are

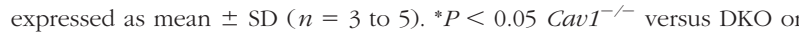
wild-type. D: Plasma levels of IL-10. Data are expressed as mean \pm SD. ( $n=$ 3 to 5). nd, not detected at basal.

\section{eNOS Activation Secondary to Cav1 Deficiency Improves Survival following LPS Challenge}

To address the survival value of de-inhibition of eNOS secondary to loss of Cav1, mortality studies were made using a higher concentration of LPS (20 mg/kg BW, i.p.). As shown in Figure 2, at 60 hours post-LPS challenge,

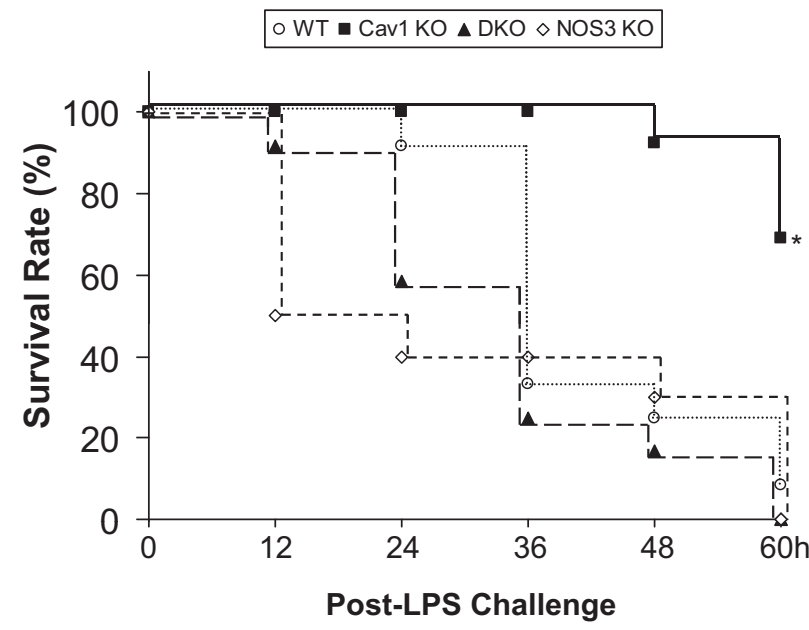

Figure 2. Survival rates following LPS challenge. Mice were challenged with LPS (20 mg/kg BW, i.p.) and housed under normal conditions. At 60 hours post-LPS challenge, $70 \%$ of $C a v 1^{-1-}$ mice survived, whereas less than $10 \%$ of mice with other three genotypes survived. Differences in the survival rates between Cav1 $^{-1-}$ and wild-type (WT), DKO, or $\mathrm{NOS3}^{-/-}$mice after LPS challenge were significant by Peto-Peto-Wilcoxon test. $n=10$ to 12 mice per group. ${ }^{*} P<0.001$.

greater than $90 \%$ of wild-type mice had died, whereas only $30 \%$ of $\mathrm{Cav1}^{-1-}$ mice were dead at this time. However, we observed $100 \%$ mortality in the DKO mice 60 hours-post LPS challenge (Figure 2).

Cav1-Regulated eNOS Activity Modulates Lung Endothelial Barrier Integrity

To determine the pathophysiological significance of chronic activation of eNOS secondary to loss of Cav1 on vascular permeability following LPS challenge, mouse lungs were used to quantify endothelial barrier function by measuring $K_{f, C}$ (lung capillary filtration coefficient). ${ }^{33}$ As shown in Figure 3, basal $K_{\mathrm{f}, \mathrm{C}}$ values were similar in wild-type, Cav1 ${ }^{-1-}$, and DKO lungs whereas it was lower in $\mathrm{NOS}^{-1-}$ lungs. At 5 hours post-LPS challenge $(7.5$ $\mathrm{mg} / \mathrm{kg}$ BW, i.p.), Cav1-/- lungs showed markedly de-

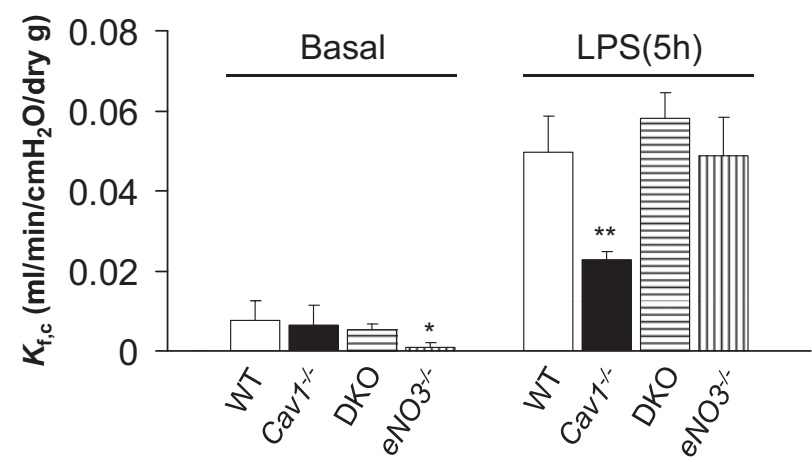

Figure 3. Restored response of lung endothelial barrier dysfunction induced by LPS in DKO mice. Lung microvessel permeability was determined by $K_{\mathrm{f}, \mathrm{c}}$ measurement. Basal, $0.2 \mathrm{ml}$ PBS; LPS, $7.5 \mathrm{mg} / \mathrm{kg} \mathrm{BW}$. Data are expressed as mean $\pm \mathrm{SD}$ ( $n=3$ to 5 per group). ${ }^{*} P<0.05$ versus basal wild-type (WT), Cav $1^{-/-}$, or DKO; ${ }^{* *} P<0.01$ versus wild-type, DKO, or $N O S 3^{-1} 5$ hours post-LPS challenge. In contrast to $\mathrm{Cav1}^{-1}$ mice, the DKO mice exhibited lung microvessel endothelial barrier dysfunction following LPS challenge to similar degree as wild-type and $\mathrm{NOS}^{-1-}$ mice. 
A

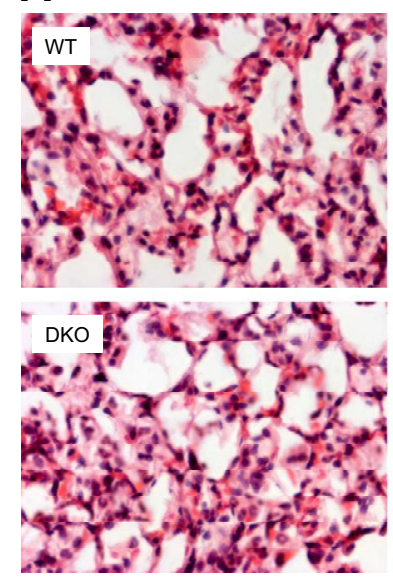

B

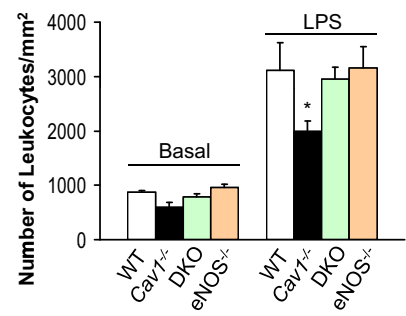

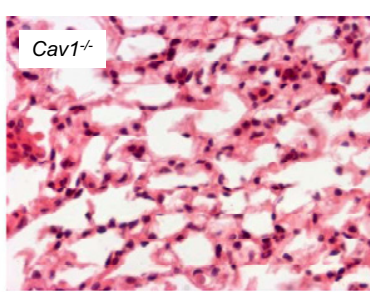

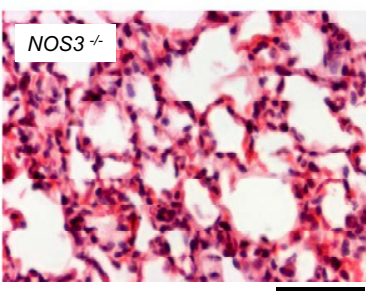

C

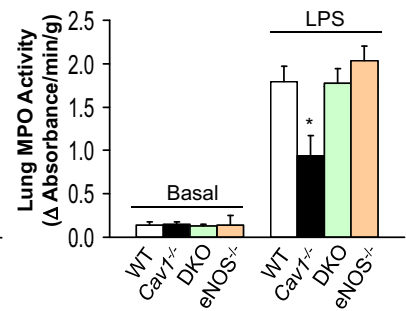

Figure 4. Prevention of LPS-induced lung injury in $C a v 1^{-/-}$mice and its reversal in DKO mice. A: Representative micrographs of H\&E staining of lung sections from mice challenged with LPS $(7.5 \mathrm{mg} / \mathrm{kg} \mathrm{BW})$. At 20 hours post-LPS challenge, lungs were fixed and processed for histological analysis. Cav1 ${ }^{-1}$ lungs showed significantly less leukocyte infiltration at 20 hours post-LPS challenge compared with other lungs. Scale bar $=200 \mu \mathrm{m}$. B: Quantification of leukocyte infiltration in lungs. Lungs from mice challenged with either PBS (Basal) or LPS $(7.5 \mathrm{mg} / \mathrm{kg} \mathrm{BW})$ for 20 hours were fixed and processed for H\&E staining. Leukocytes were counted using a stereomicroscopy. Data are expressed as mean $\pm \mathrm{SD}(n=4$ to 5$) .{ }^{*} P<0.05$ versus wild-type (WT), $\mathrm{DKO}$, or $\mathrm{NOS}^{-1-}$. C: MPO activities in lungs challenged with either PBS (Basal) or LPS $(7.5 \mathrm{mg} / \mathrm{kg} \mathrm{BW}, 20$ hours). Data are expressed as mean $\pm \mathrm{SD}$ ( $n=4$ to 5 ). ${ }^{*} P<0.05$ versus wild-type, DKO, or $N O S 3^{->}$

creased $K_{f, c}$ response, as compared with wild-type lungs indicating decreased lung vascular permeability. The reduced response of Cav1 ${ }^{-1-}$ lungs was restored in DKO lungs to the level of wild-type lungs (Figure 3).

\section{Cav1-Regulated eNOS Activity Dampens Lung Inflammation}

To further investigate the role of Cav1-regulated eNOS in LPS-induced lung inflammation, H\&E staining of lung sections was performed and leukocyte infiltration following LPS challenge was quantified. As shown in Figure 4, A-C, Cav1 ${ }^{-1-}$ lungs had significantly less leukocyte infiltration 20 hours post-LPS challenge $(7.5 \mathrm{mg} / \mathrm{kg} \mathrm{BW}$, i.p.) compared with wild-type, DKO, or $\mathrm{NOS}^{-1-}$. There was also decreased lung MPO activity, a measure of neutrophil infiltration, in $\mathrm{Cav1}^{-1-}$ mice at 20 hours post-LPS challenge, and the responses restored in DKO lungs to the levels in wild-type. In addition, we determined the expression of pro-inflammatory molecules in lungs following LPS challenge $(7.5 \mathrm{mg} / \mathrm{kg} \mathrm{BW}$, i.p.). At 2 hours postLPS challenge, Cav1 ${ }^{-1-}$ lungs produced significantly less $\mathrm{TNF} \alpha$ compared with wild-type, whereas the DKO

A

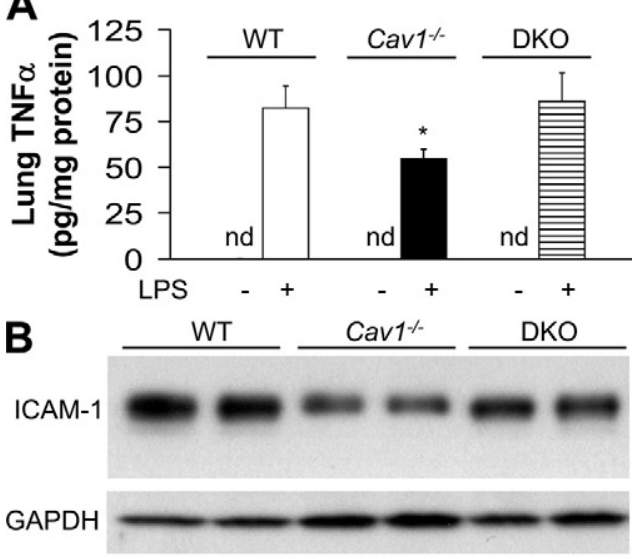

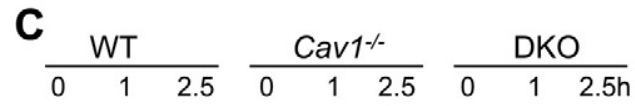

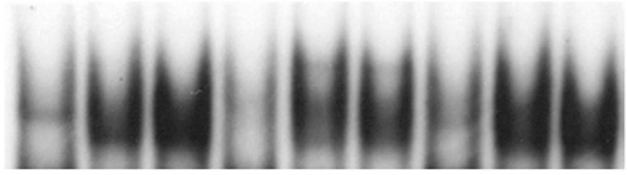

D

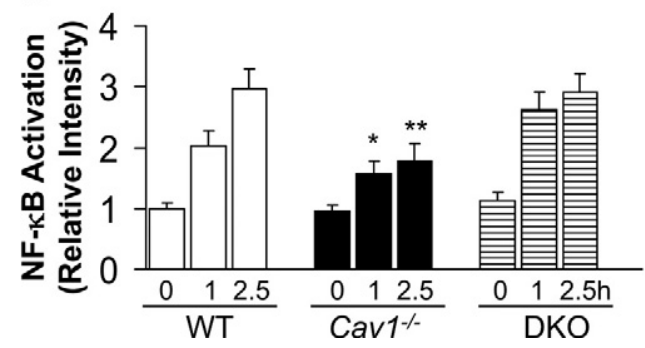

Figure 5. LPS-induced reduction in expression of TNF $\alpha$ and ICAM-1 and $\mathrm{NF}-\kappa \mathrm{B}$ activation in lungs of $\mathrm{Cav1}^{-\prime-}$ mice is reversed in DKO mice. A: Mouse lung TNF $\alpha$ determined by enzyme-linked immunosorbent assay. Lungs were collected from mice challenged with PBS or LPS $(7.5 \mathrm{mg} / \mathrm{kg} \mathrm{BW}$, i.p.) for 2 hours and lysed with radioimmunoprecipitation assay buffer. Approximately $100 \mu \mathrm{g}$ of each lung lysate was used for TNF $\alpha$ enzyme-linked immunosorbent assay. Data are expressed as mean $\pm \mathrm{SD}(n=4$ to 5$) .{ }^{*} P<$ 0.05 versus wild-type-LPS or DKO-LPS. nd, not detected. Reduced LPSinduced TNF $\alpha$ expression in Cav1 $1^{-/}$lungs was restored in DKO lungs to the same degree as wild-type (WT). B: Western blot analysis of ICAM-1 expression in mouse lungs following LPS challenge. Two hours post-LPS challenge, mouse lungs were collected for Western blot analysis of ICAM-1 expression. In contrast to its expression in Cav1 $1^{-/}$lungs, ICAM-1 expression in DKO lungs was restored to similar levels as in wild-type lungs. C-D: $\mathrm{NF}-\kappa \mathrm{B}$ activation in mouse lungs following LPS challenge $(7.5 \mathrm{mg} / \mathrm{kg} \mathrm{BW}$, i.p.). Lungs were collected from mice without LPS (0 hours) or post-LPS challenge at the indicated time points ( 1 and 2.5 hours) and nuclei extracts were used for gel shift assay. Following LPS challenge, Cav1 $1^{-/}$lungs exhibited significantly less NF- $\kappa \mathrm{B}$ activation compared with wild-type and DKO lungs as shown by representative gel shift assay $(\mathbf{C})$ and densitometry analysis of each band (D). Data are expressed as mean $\pm \mathrm{SD}(n=3)$. ${ }^{*} P<$ 0.05 versus either wild-type-LPS 1 hour or DKO-LPS 1 hour; ${ }^{* *} P<0.05$ versus wild-type-LPS2.5 hours or DKO-LPS 2.5 hours.

lungs produced the same level of TNF $\alpha$ as wild-type (Figure 5A). The expression of ICAM-1, another inflammatory marker mediating leukocyte and endothelial cell adhesion, in lungs was also analyzed. LPS-induced ICAM-1 expression in Cav1 ${ }^{-1-}$ lungs was inhibited compared with wild-type whereas LPS-induced ICAM-1 expression in DKO lungs was similar to in wild-type lungs (Figure 5B). NF- $\kappa \mathrm{B}$ activation was significantly less in Cav1 ${ }^{-1-}$ lungs in response to LPS, as compared with 
A

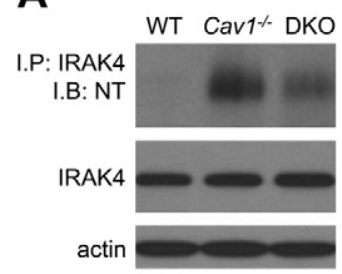

C

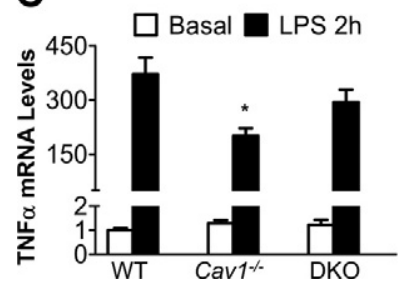

B

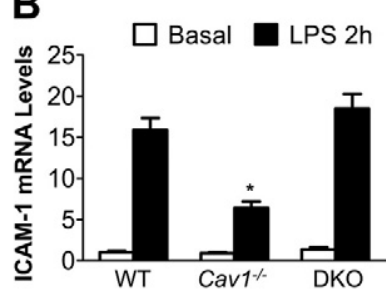

D

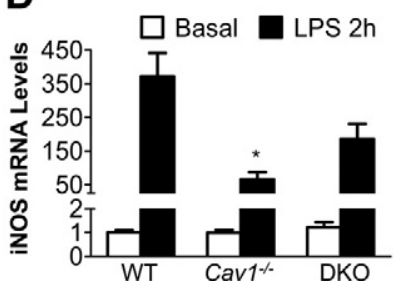

Figure 6. eNOS activation-induced IRAk4 nitration in $\mathrm{Cav1}^{-/-}$endothelial cells. A: Western blot analysis of IRAk4 nitration in primary culture of mouse lung endothelial cells. Eighty micrograms of each cell lysate precleared with IgG were immunoprecipitated with $2 \mu \mathrm{g}$ of anti-IRAK4 and then immunoblotted with anti-nitrotyrosine (NT). The same blot was reprobed with antiIRAK4 antibody. Anti-GAPDH was used as a loading control. Prominent IRAK4 nitration was detected in Cav1 ${ }^{-1}$ endothelial cells whereas eNOS deletion resulted in drastic decrease of IRAK4 nitration in DKO endothelial cells. The experiment was repeated twice with similar data. B-D: Decreased induction of $\operatorname{ICAM}-1(\mathbf{B}), \operatorname{TNF} \alpha(\mathbf{C})$, and iNOS (D) in $\operatorname{Cav} 1^{-/-}$endothelial cells 2 hours post-LPS challenge was restored in DKO endothelial cells. Total RNA isolated from primary cultures of wild-type (WT), Cav1 ${ }^{-/-}$or DKO lung endothelial cells were used for quantitative real time RT-PCR analysis. Data are expressed as mean $\pm \mathrm{SD}(n=3) .{ }^{*} P<0.01$ versus wild-type or DKO 2 hours post-LPS.

wild-type (Figure 5C and 5D). However, DKO lungs displayed the same level of NF- $\kappa \mathrm{B}$ activation as wild-type lungs in response to LPS (Figure 5, C and D).

\section{Dampened TLR4 Signaling in Cav1 ${ }^{-1-}$ Mice Involves eNOS Activation-Mediated IRAK4 Nitration}

We have recently shown that Cav1 deficiency results in marked increase in nitrative stress due to excessive production of superoxide and eNOS-derived NO, which form peroxynitrite and thereby modify proteins through tyrosine nitration. ${ }^{31}$ To determine whether Cav1 deficiency induces nitration of IRAK4, the essential component of TLR4 signaling, , ,16,17 mouse lung endothelial cells were isolated and IRAK4 nitration was detected by Western blot analysis. As shown in Figure 6A, prominent nitration of IRAK4 was detected in Cav1 ${ }^{-1-}$ endothelial cells whereas eNOS deletion drastically inhibited IRAK4 nitration. Accordingly, LPS-induced production of pro-inflammatory molecules such as ICAM-1 (Figure 6B), TNF $\alpha$ (Figure 6C) and iNOS (Figure 6D) expression was markedly decreased in $\mathrm{Cav1}^{-1-}$ endothelial cells compared with wild-type whereas restored in DKO.

To further determine the consequence of tyrosine nitration on IRAK4 kinase activity, in vitro nitration and kinase assay were performed. As shown in Figure 7, A-B, peroxynitrite incubation resulted in IRAK4 nitration and impairment of kinase activity in a dose-dependent manner. These data suggest that loss of Cav1 regulation of

A

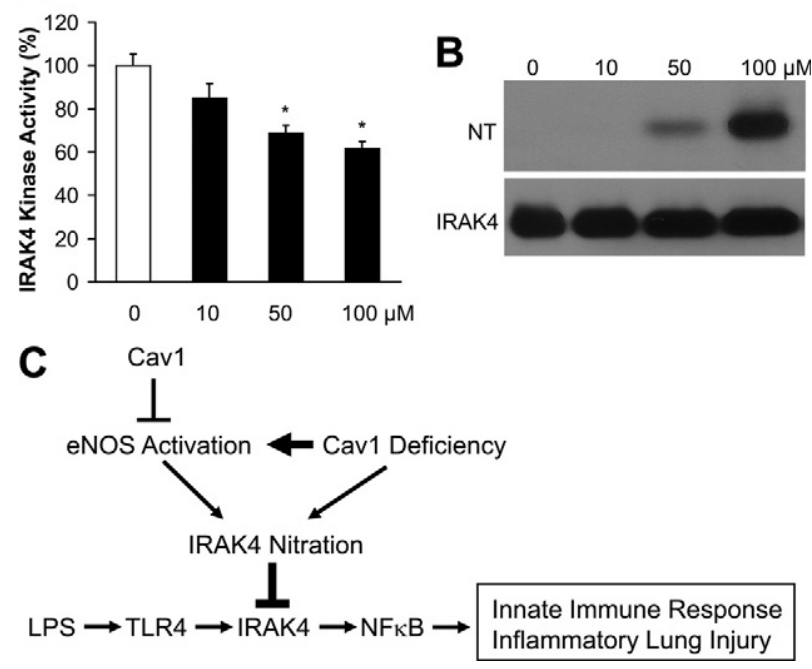

Figure 7. IRAK4 nitration results in impairment of kinase activity. A-B Following a 20 minutes-incubation with the indicated concentrations of peroxynitrite at room temperature, aliquots of IRAK 4 reaction mixtures were used to determine kinase activity $(\mathbf{A})$ and tyrosine nitration $(\mathbf{B})$. Data are expressed as mean $\pm \mathrm{SD}(n=3) .{ }^{*} P<0.05$. Peroxynitrite incubation impairs IRAK4 kinase activity in a dose-dependent manner (A). Representative Western blotting $(n=3)$ demonstrates IRAK4 nitration induced by peroxynitrite (B). NT, anti-nitrotyrosine. C: Proposed model of Cav1 deficiency-induced dampening of TLR4 signaling. Cav1 is a critical negative regulator of eNOS. Cav1 deficiency leads to eNOS activation and resultant post-translational modification of IRAK 4 through tyrosine nitration. IRAK4 nitration impairs its kinase activity and thereby inhibits TLR4 signaling in response to LPS challenge. Impaired TLR 4 signaling results in dampening of the innate immune response and subsequent mitigation of inflammatory lung injury through decreased NF $\kappa \mathrm{B}$ activation.

eNOS results in impairment of IRAK4 activity through tyrosine nitration and thereby mediates decreased $\mathrm{NF}-\kappa \mathrm{B}$ activation and inflammatory lung injury in Cav1 ${ }^{-1-}$ mice in response to LPS challenge (Figure $7 \mathrm{C}$ ).

\section{Discussion}

We present here the first genetic evidence of the physiological significance of Cav1 modulation of eNOS activity in regulating TLR signaling. We demonstrated that deinhibition of eNOS resulted in decreased production of pro-inflammatory molecules and $\mathrm{NF}-\kappa \mathrm{B}$ activation in response to LPS challenge in Cav1 ${ }^{-1-}$ mice. We also observed that the $\mathrm{Cav1}^{-/-} / \mathrm{NOS}^{-/-}$DKO mice exhibited the same inflammatory lung injury and mortality rate following LPS challenge as wild-type mice, whereas loss of Cav1 led to less lung injury and mortality. These protective effects are ascribed to IRAK4 nitration and resultant impairment of kinase activity induced by eNOS activation secondary to Cav1 deficiency. Thus, the results show that Cav1 modulation of eNOS activity is a key regulator of innate immunity and inflammatory lung injury in response to LPS through regulation of IRAK4 kinase activity.

Previous studies have implicated that Cav1 negatively regulates eNOS function. In vitro studies demonstrated that Cav1 through its scaffolding domain (amino acids 82 to 101) binds with the eNOS oxygenase domain and inhibits its catalytic activity. ${ }^{36,37}$ It was shown that a peptide containing a cell permeable leader sequence and 
Cav1 scaffolding domain is a potent inhibitor of eNOS activity in isolated vessels and also blocked inflammation and microvascular hyperpermeability in mice. ${ }^{38}$ Consistently, it has been shown that plasma NO level was increased in $\mathrm{Cav1}^{-1-}$ mice. ${ }^{26}$ However, there is no direct evidence that eNOS activation is responsible for the increase. We have shown that the increased production of plasma NO in $\mathrm{Cav1}^{-1-}$ mice is ascribed to eNOS activation.

We observed a marked decrease in the plasma levels of pro-inflammatory mediators TNF $\alpha$ and MIP- $1 \alpha$ in Cav1 ${ }^{-1-}$ mice following LPS challenge but not the noninflammatory cytokine IL-10. The markedly dampened response was the result of de-inhibition of eNOS since the release of these mediators was the same in DKO and wild-type mice. We also observed that production of proinflammatory mediators such as TNF $\alpha$, ICAM- 1 , and iNOS was significantly reduced in endothelial cells isolated from Cav1 ${ }^{-\prime-}$ lungs in response to LPS challenge, as compared with that in wild-type endothelial cells, whereas deletion of eNOS resulted in restored production of these pro-inflammatory molecules in endothelial cells isolated from the DKO lungs. Thus, our results support the hypothesis that NO produced from activated eNOS secondary to loss of Cav1 is responsible for preventing LPS-induced production of pro-inflammatory molecules in $\mathrm{Cav1}^{-1-}$ mice.

Although eNOS-derived NO is in general considered protective under normal physiological conditions, the role of eNOS in sepsis remains unclear and contradictory in the literature. One study has shown eNOS ${ }^{-/-}$mice exhibited no difference in survival in response to LPS challenge compared with wild-type mice, ${ }^{35}$ whereas another study identified a pro-inflammatory role for eNOS-derived $\mathrm{NO}$ and showed resistance to endotoxic shock in eNOS ${ }^{-/-}$mice. ${ }^{39}$ In contrast to these studies, chronic eNOS overexpression in the endothelium of transgenic mice resulted in resistance to LPS-induced hypotension, lung injury, and death..$^{40}$ Our data clearly demonstrated the important protective role of eNOS-derived NO in preventing LPS-induced lung injury and mortality and identified a novel mechanism of this protection. eNOS activation secondary to loss of Cav1 inhibited LPS-induced production of pro-inflammatory cytokines in vitro and in vivo and resulted in reduced lung injury and mortality. These protective effects were mediated by eNOS activation-dependent IRAK4 nitration and resultant impairment of kinase activity.

It has been shown that the kinase activity of IRAK4 is critical for TLR-mediated immune response. ${ }^{16,41}$ The IRAK4 kinase-inactive-knock-in mice are resistant to TLR4 signaling-induced shock response due to impaired TLR-mediated induction of pro-inflammatory cytokines and chemokines. ${ }^{16,41}$ We demonstrated that peroxynitrite induces IRAK4 nitration and impairs its kinase activity in a dose-dependent manner in vitro. In Cav1 ${ }^{-1-}$ endothelial cells, we observed prominent IRAK4 nitration, which was drastically decreased by deletion of eNOS. These data support the notion that eNOS activation secondary to loss of Cav1 impairs IRAK4 kinase activity through nitration and thereby dampens TLR4 signaling. Thus, our study provides a novel mechanism of eNOS in regulating TLR signaling and innate immunity through its ability to modulate IRAK4 kinase activity.

It was reported that $\mathrm{Cav1}^{-/-}$mice exhibited reduced lung injury and increased survival following LPS challenge through decreased NF- $\kappa \mathrm{B}$ activation. ${ }^{29}$ The protective effect seen in $\mathrm{Cav}^{-1-}$ mice was likely due to increased NO production since treatment with nitro-Larginine (a NOS inhibitor) restored LPS-induced NF- $\kappa \mathrm{B}$ activation in $\mathrm{Cav1}^{-1-}$ lungs and increased mortality. However, it is not clear whether the protective effects are mediated by eNOS-derived NO since there are fundamental caveats with the previous study. First, there is no eNOS-specific inhibitor; nitro-L-arginine used at dose of $100 \mathrm{mg} / \mathrm{kg}$ BW confers inhibitory effects on all three NOS. ${ }^{18,42}$ Thus, it is not possible to determine the role of eNOS activation in regulating LPS-induced NF- $\kappa$ B activation and lung injury. Moreover, all NOS inhibitors have actions that may be unrelated to the inhibition of NOS. ${ }^{18}$ Therefore, the present study using $\mathrm{Cav} 1^{-1-} / \mathrm{eNOS}^{-/-}$ mice shows convincingly the essential role of production of eNOS-derived NO in modulating LPS-induced inflammatory response and lung injury. We also demonstrated that reduced lung injury and mortality in Cav $1^{-1-}$ mice following LPS challenge was attributed to the activation of eNOS and resultant impairment of IRAK4 kinase activity. We therefore conclude that Cav1 through its ability to regulate eNOS-derived NO production is a primary determinant of NF- $\kappa \mathrm{B}$ activation and lung inflammatory response to LPS. NO-mediated inhibition of NF- $\kappa \mathrm{B}$ activation has been ascribed to NO-mediated stabilization of $1 \kappa \mathrm{B} \alpha,{ }^{43} \mathrm{NO}$-elicited nitrosylation of Cys on $\mathrm{p} 50$ subunit, ${ }^{44}$ and rapid interaction with reactive oxygen species. ${ }^{45}$ Here, our study provides a novel mechanism of NOmediated inhibition of NF- $\kappa \mathrm{B}$ activation through IRAK4 nitration and resultant impairment of kinase activity in the context of Cav1 deficiency. In this sense targeting Cav1eNOS interaction may represent a novel therapeutic approach to terminate NF- $\kappa \mathrm{B}$ activation during immune response and thereby limit inflammatory lung injury.

In summary, the present study provides clear evidence of the physiological significance of Cav1 modulation of eNOS activity in regulating innate immunity and sepsisinduced lung injury. eNOS activation secondary to Cav1 deficiency induces IRAK4 nitration and subsequent impairment of its kinase activity, and thereby selectively dampens TLR signaling mediated by MyD88-IRAK4 pathway. Targeting Cav1-eNOS interaction during sepsis may represent a novel therapeutic approach for the treatment of acute lung injury.

\section{Acknowledgment}

We thank Yubin Wu for his expert support on primary culture of mouse lung endothelial cells.

\section{References}

1. Han J, Ulevitch RJ: Limiting inflammatory responses during activation of innate immunity. Nat Immunol 2005, 6:1198-1205 
2. Medzhitov R, Janeway CA Jr: Decoding the patterns of self and nonself by the innate immune system. Science 2002, 296:298-300

3. Fearon DT, Locksley RM: The instructive role of innate immunity in the acquired immune response. Science 1996, 272:50-53

4. Krieg AM, Yi AK, Matson S, Waldschmidt TJ, Bishop GA, Teasdale R, Koretzky GA, Klinman DM: CpG motifs in bacterial DNA trigger direct B-cell activation. Nature 1995, 374:546-549

5. Janeway CA Jr, Medzhitov R: Innate immune recognition. Annu Rev Immunol 2002, 20:197-216

6. Medzhitov R: Toll-like receptors and innate immunity. Nat Rev Immunol 2001, 1:135-145

7. Akira S, Takeda K, Kaisho T: Toll-like receptors: critical proteins linking innate and acquired immunity. Nat Immunol 2001, 2:675-680

8. Suzuki N, Suzuki S, Duncan GS, Millar DG, Wada T, Mirtsos C, Takada H, Wakeham A, Itie A, Li S, Penninger JM, Wesche H, Ohashi PS, Mak TW, Yeh WC: Severe impairment of interleukin-1 and Toll-like receptor signalling in mice lacking IRAK-4. Nature 2002, 416:750-756

9. Cao Z, Xiong J, Takeuchi M, Kurama T, Goeddel DV: TRAF6 is a signal transducer for interleukin-1. Nature 1996, 383:443-446

10. Cao Z, Henzel WJ, Gao X: IRAK: a kinase associated with the interleukin-1 receptor. Science 1996, 271:1128-1131

11. Ninomiya-Tsuji J, Kishimoto K, Hiyama A, Inoue J, Cao Z, Matsumoto K: The kinase TAK 1 can activate the NIK-I kappaB as well as the MAP kinase cascade in the IL-1 signalling pathway. Nature 1999, 398: 252-256

12. Schenk P, Madl C, Rezaie-Majd S, Lehr S, Muller C: Methylene blue improves the hepatopulmonary syndrome. Ann Intern Med 2000, 133:701-706

13. Li Q, Verma IM: NF-kappaB regulation in the immune system. Nat Rev Immunol 2002, 2:725-734

14. Luo B, Liu L, Tang L, Zhang J, Ling Y, Fallon MB: ET-1 and TNF-alpha in HPS: analysis in prehepatic portal hypertension and biliary and nonbiliary cirrhosis in rats. Am J Physiol Gastrointest Liver Physiol 2004, 286:G294-G303

15. Beutler B, Rietschel ET: Innate immune sensing and its roots: the story of endotoxin. Nat Rev Immunol 2003, 3:169-176

16. Kim TW, Staschke K, Bulek K, Yao J, Peters K, Oh KH, Vandenburg Y, Xiao H, Qian W, Hamilton T, Min B, Sen G, Gilmour R, Li X: A critical role for IRAK4 kinase activity in Toll-like receptor-mediated innate immunity. J Exp Med 2007, 204:1025-1036

17. Picard C, Puel A, Bonnet M, Ku CL, Bustamante J, Yang K, Soudais C, Dupuis S, Feinberg J, Fieschi C, Elbim C, Hitchcock R, Lammas D, Davies G, Al-Ghonaium A, Al-Rayes H, Al-Jumaah S, Al-Hajjar S, Al-Mohsen IZ, Frayha HH, Rucker R, Hawn TR, Aderem A, Tufenkej H, Haraguchi S, Day NK, Good RA, Gougerot-Pocidalo MA, Ozinsky A, Casanova JL: Pyogenic bacterial infections in humans with IRAK-4 deficiency. Science 2003, 299:2076-2079

18. Bogdan C, Rollinghoff M, Diefenbach A: The role of nitric oxide in innate immunity. Immunol Rev 2000, 173:17-26

19. Ignarro LJ: Nitric oxide as a unique signaling molecule in the vascular system: a historical overview. J Physiol Pharmacol 2002, 53:503-514

20. MacMicking J, Xie QW, Nathan C: Nitric oxide and macrophage function. Annu Rev Immunol 1997, 15:323-350

21. Albrecht EW, Stegeman CA, Heeringa $\mathrm{P}$, Henning $\mathrm{RH}$, van Goor $\mathrm{H}$ : Protective role of endothelial nitric oxide synthase. J Pathol 2003, 199:8-17

22. Naseem KM: The role of nitric oxide in cardiovascular diseases. Mol Aspects Med 2005, 26:33-65

23. Fulton D, Gratton JP, Sessa WC: Post-translational control of endothelial nitric oxide synthase: why isn't calcium/calmodulin enough? J Pharmacol Exp Ther 2001, 299:818-824

24. Rothberg KG, Heuser JE, Donzell WC, Ying YS, Glenney JR, Anderson RG: Caveolin, a protein component of caveolae membrane coats. Cell 1992, 68:673-682

25. Michel T, Feron O: Nitric oxide synthases: which, where, how, and why? J Clin Invest 1997, 100:2146-2152

26. Zhao YY, Liu Y, Stan RV, Fan L, Gu Y, Dalton N, Chu PH, Peterson K, Ross $\mathrm{J} \mathrm{Jr}$, Chien KR: Defects in caveolin- 1 cause dilated cardiomyopathy and pulmonary hypertension in knockout mice. Proc Natl Acad Sci USA 2002, 99:11375-11380

27. Drab M, Verkade P, Elger M, Kasper M, Lohn M, Lauterbach B, Menne J, Lindschau C, Mende F, Luft FC, Schedl A, Haller H, Kurzchalia TV: Loss of caveolae, vascular dysfunction, and pulmo- nary defects in caveolin-1 gene-disrupted mice. Science 2001, 293: 2449-2452

28. Razani B, Engelman JA, Wang XB, Schubert W, Zhang XL, Marks CB, Macaluso F, Russell RG, Li M, Pestell RG, Di Vizio D, Hou H Jr, Kneitz B, Lagaud G, Christ GJ, Edelmann W, Lisanti MP: Caveolin-1 null mice are viable but show evidence of hyperproliferative and vascular abnormalities. J Biol Chem 2001, 276:38121-38138

29. Garrean S, Gao XP, Brovkovych V, Shimizu J, Zhao YY, Vogel SM, Malik AB: Caveolin-1 regulates NF-kappaB activation and lung inflammatory response to sepsis induced by lipopolysaccharide. J Immunol 2006, 177:4853-4860

30. Okamoto T, Schlegel A, Scherer PE, Lisanti MP: Caveolins, a family of scaffolding proteins for organizing "preassembled signaling complexes" at the plasma membrane. J Biol Chem 1998, 273: 5419-5422

31. Zhao YY, Zhao YD, Mirza MK, Huang JH, Potula HH, Vogel SM, Brovkovych V, Yuan JX, Wharton J, Malik AB: Persistent eNOS activation secondary to caveolin-1 deficiency induces pulmonary hypertension in mice and humans through PKG nitration. J Clin Invest 2009, 119:2009-2018

32. Zhao YY, Gao XP, Zhao YD, Mirza MK, Frey RS, Kalinichenko VV Wang IC, Costa RH, Malik AB: Endothelial cell-restricted disruption of FoxM1 impairs endothelial repair following LPS-induced vascular injury. J Clin Invest 2006, 116:2333-2343

33. Gao X, Xu N, Sekosan M, Mehta D, Ma SY, Rahman A, Malik AB: Differential role of CD18 integrins in mediating lung neutrophil sequestration and increased microvascular permeability induced by Escherichia coli in mice. J Immunol 2001, 167:2895-2901

34. Gao XP, Standiford TJ, Rahman A, Newstead M, Holland SM, Dinauer MC, Liu QH, Malik AB: Role of NADPH oxidase in the mechanism of lung neutrophil sequestration and microvessel injury induced by Gram-negative sepsis: studies in p47phox-/- and gp91phox-/mice. J Immunol 2002, 168:3974-3982

35. Shesely EG, Maeda N, Kim HS, Desai KM, Krege JH, Laubach VE, Sherman PA, Sessa WC, Smithies O: Elevated blood pressures in mice lacking endothelial nitric oxide synthase. Proc Natl Acad Sci USA 1996, 93:13176-13181

36. Thorens JB, Junod AF: Hypoxaemia and liver cirrhosis: a new argument in favour of a "diffusion-perfusion defect." Eur Respir J 1992, 5:754-756

37. Garcia-Cardena G, Fan R, Stern DF, Liu J, Sessa WC: Endothelial nitric oxide synthase is regulated by tyrosine phosphorylation and interacts with caveolin-1. J Biol Chem 1996, 271:27237-27240

38. Bucci M, Gratton JP, Rudic RD, Acevedo L, Roviezzo F, Cirino G, Sessa WC: In vivo delivery of the caveolin-1 scaffolding domain inhibits nitric oxide synthesis and reduces inflammation. Nat Med 2000, 6:1362-1367

39. Connelly L, Madhani M, Hobbs AJ: Resistance to endotoxic shock in endothelial nitric-oxide synthase (eNOS) knock-out mice: a pro-inflammatory role for eNOS-derived no in vivo. J Biol Chem 2005, 280:10040-10046

40. Yamashita T, Kawashima S, Ohashi Y, Ozaki M, Ueyama T, Ishida T, Inoue N, Hirata K, Akita H, Yokoyama M: Resistance to endotoxin shock in transgenic mice overexpressing endothelial nitric oxide synthase. Circulation 2000, 101:931-937

41. Kawagoe T, Sato S, Jung A, Yamamoto M, Matsui K, Kato H, Uematsu S, Takeuchi O, Akira S: Essential role of IRAK-4 protein and its kinase activity in Toll-like receptor-mediated immune responses but not in TCR signaling. J Exp Med 2007, 204:1013-1024

42. Cirino G, Fiorucci S, Sessa WC: Endothelial nitric oxide synthase: the Cinderella of inflammation? Trends Pharmacol Sci 2003, 24:91-95

43. Peng HB, Libby P, Liao JK: Induction and stabilization of I kappa B alpha by nitric oxide mediates inhibition of NF-kappa B. J Biol Chem 1995, 270:14214-14219

44. delaTorre A, Schroeder RA, Punzalan C, Kuo PC: Endotoxin-mediated S-nitrosylation of p50 alters NF-kappa B-dependent gene transcription in ANA-1 murine macrophages. J Immunol 1999, 162: 4101-4108

45. Chandel NS, Trzyna WC, McClintock DS, Schumacker PT: Role of oxidants in NF-kappa B activation and TNF-alpha gene transcription induced by hypoxia and endotoxin. J Immunol 2000, 165: 1013-1021 